\title{
A Study on the Mental Health Status of Peasant-workers' Accompanying Children and the Countermeasures
}

\author{
Fang Bi-ji ${ }^{1, a, ~}$, Zheng Ya-nan ${ }^{2, b}$, Liu Cai-xia ${ }^{3, c}$ \\ ${ }^{1}$ Department of Psychology, Gannan Medical Universtiy, Ganzhou, 341000, China \\ ${ }^{2}$ Department of Psychology, Gannan Medical Universtiy, Ganzhou, 341000, China \\ ${ }^{3}$ Library of Gannan Medical Universtiy, Ganzhou, 341000, China \\ aemail: xgfbj@126.com, bemail: marine873926@sina.com, email: 82477534@qq.com, \\ "corresponding author
}

Keywords: peasant-worker, accompanying children, mental health, mental health education

\begin{abstract}
Objective: To understand the mental health status of peasant-workers' accompanying children, explore the countermeasures, and provide empirical reference for the work of mental health education. Methods: With random sampling, 786 peasant-workers' accompanying children chosen from eight schools for migrant workers' children were surveyed with the questionnaire of Mental Health Test (MHT). The statistical analysis is carried out by SPSS 15.0. Results: The mental problems incidence rate among peasant-workers' accompanying children is significantly higher than that of general population $(\mathrm{p}<0.05)$. The mental health status of peasant-workers' accompanying children shows no difference in the variable of gender $(p>0.05)$, but significant difference can be seen in the variables of parenting and only-child or not $(p<0.05)$. Conclusion: The mental health status of peasant-workers' accompanying children is not optimistic. It is necessary to strengthen the work for mental health education to peasant-workers' accompanying children with the contributions of family, school and society.
\end{abstract}

\section{Introduction}

With the countryside surplus-labor shifting to the urban, the specific group of peasant-workers gradually formed in the late 1980s in China. As the stream of family-based population flows with an increasingly high speed, the group of peasant-workers' accompanying children gradually came on a large scale [1]. In order to make the study operable, the peasant-workers' accompanying children in the study are defined as the juveniles who flow into cities with guardians (mainly parents), stay longer than six months and attend schools for migrant workers' children [2]. On the one hand, researches show that the mental health status of peasant-workers' accompanying children is generally poor due to the influence of adverse circumstances [3] [4]. On the other hand, researches on the immigrant children suggest that the sufferings in the course of migrating may train their mental quality, which makes them get better mental health than native children [5].

It is well-known that the mental health of juveniles is deeply affected by the living environments. The period known as adolescence is a time of dramatic change in both body and mentality. The mental health of juveniles is easily affected by various factors inside and outside. Due to the influence of changing in family, daily life, learning and so on, peasant-workers' accompanying children are suffering tremendous trial and threat. It is significant to have a proper knowledge about the mental health status of peasant-workers' accompanying children, in order to develop positively mental health education which helps promote their healthy development. It is also beneficial to promote the smooth transferring of surplus labors in rural areas, enhance social stability and progress, and construct a harmonious society.

\section{Methods}

Measure

Mental Health Test (MHT). The questionnaire, which is composed of 8 symptom scales such as 
Learning Anxiety, Interpersonal Anxiety, Lonely Tendency, Self-accusation Tendency, Sensitivity Tendency, Body Symptom, Terror Tendency, Impulse Tendency, and one validity scale, totally 100 single-choice questions, was designed by Professor Zhou in 1991. The subjects must choose the right answer based on their actuality in each item, 1 point for choosing "yes", 0 point for choosing "no". The result is distrusted when the validity scale scores 7 and above. It shows that the subject may exist the corresponding mental problem when the symptom scale scores 8 and above, or the questionnaire totally scores 65 and above. Researches show that the questionnaire has high reliability and validity, and can be used as a tool to conduct mental health survey for the primary and middle school students [6].

\section{Subjects}

1200 students from 8 migrant children schools and 2 ordinary schools were recruited to complete the survey with the help of the teachers. When they finished, the questionnaires were taken back immediately. 1174 valid questionnaires were collected, among which 786 are finished by peasant-workers' accompanying children (439 males, 347 females; 235 only-child, 551 non-only-child; 428 from democratic parenting family, 358 from authoritarian parenting family), 388 by local students.

\section{Statistical Tool}

The results are statistically analyzed by SPSS 15.0 .

\section{Results}

\section{The Mental Health Status of Peasant-workers' Accompanying Children}

Generally thinking, the mental health status of ordinary people is roughly normal distribution. $\mathrm{X}^{2}$ test is performed on the actual number of different scores in the scales of MHT with the theoretical number of normal distribution. The results were shown as follows in Table 1.

Table 1 the Status of Mental Health of the Peasant-workers' Accompanying Children

\begin{tabular}{ccccc}
\hline Scales & $\begin{array}{c}\text { Scores } \\
{[\mathrm{M} \pm \mathrm{SD}]}\end{array}$ & $\begin{array}{c}8 \text { Points and Above } \\
{[\text { persons] }}\end{array}$ & $\begin{array}{c}\text { 7 Points and Below } \\
\text { [persons] }\end{array}$ & $\mathrm{X}^{2}$ \\
\hline Learning Anxiety & $8.40 \pm 2.84$ & 478 & 308 & $552.37^{* *}$ \\
Interpersonal Anxiety & $5.35 \pm 2.26$ & 78 & 708 & $13.23^{* *}$ \\
Lonely Tendency & $4.42 \pm 2.52$ & 49 & 737 & 0.96 \\
Self-accusation Tendency & $6.26 \pm 2.45$ & 139 & 647 & $61.79^{* *}$ \\
Sensitivity Tendency & $5.98 \pm 2.09$ & 134 & 652 & $57.10^{* *}$ \\
Body Symptom & $6.53 \pm 2.93$ & 154 & 632 & $76.42^{* *}$ \\
Terror Tendency & $5.24 \pm 2.67$ & 71 & 715 & $9.32^{* *}$ \\
Impulse Tendency & $4.26 \pm 2.49$ & 44 & 742 & 0.20 \\
Total scale & $46.44 \pm 13.82$ & 65 Points and & 64 Points and & $145.73^{* *}$ \\
& & Above: 217 persons & Below: 569 persons \\
\hline
\end{tabular}

$* *=p<.01$

From Table 1, we know that the mental problems incidence rate of peasant-workers' accompanying children is significantly higher than that of general people in the six symptom scales of Learning Anxiety, Interpersonal Anxiety, Self-accusation Tendency, Sensitivity Tendency, Body Symptom, Terror Tendency, and the total scale. Further analysis shows that the peasant-workers' accompanying children score significantly higher than local children in the 8 symptom scales and the total scale, which indicates that the mental health state of peasant-workers' accompanying children is poor. The results were shown as follows in Table 2. 
Table 2 the Comparison of Mental Health between the Peasant-workers' Accompanying Children and Local Children

\begin{tabular}{cccc}
\hline Scales & $\begin{array}{c}\text { Scores of Peasant-workers' } \\
\text { Accompanying Children[M } \pm \text { SD] }\end{array}$ & $\begin{array}{c}\text { Scores of Local Children } \\
{[\mathrm{M} \pm \mathrm{SD}]}\end{array}$ & $\mathrm{T}$ \\
\hline Learning Anxiety & $8.40 \pm 2.84$ & $7.37 \pm 3.22$ & $5.59^{* *}$ \\
Interpersonal Anxiety & $5.35 \pm 2.26$ & $4.42 \pm 2.12$ & $6.77^{* *}$ \\
Lonely Tendency & $4.42 \pm 2.52$ & $3.80 \pm 2.57$ & $3.94^{* *}$ \\
Self-accusation Tendency & $6.26 \pm 2.45$ & $5.65 \pm 2.50$ & $3.99^{* *}$ \\
Sensitivity Tendency & $5.98 \pm 2.09$ & $5.64 \pm 2.46$ & $2.47^{*}$ \\
Body Symptom & $6.53 \pm 2.93$ & $5.46 \pm 3.17$ & $5.73^{* *}$ \\
Terror Tendency & $5.24 \pm 2.67$ & $3.93 \pm 2.72$ & $7.86^{* *}$ \\
Impulse Tendency & $4.26 \pm 2.49$ & $3.88 \pm 2.50$ & $2.46^{*}$ \\
Total scale & $46.44 \pm 13.82$ & $40.35 \pm 14.20$ & $7.04^{* *}$ \\
\hline
\end{tabular}

$*=\mathrm{p}<.05 ; * *=\mathrm{p}<.01$

Gap Analysis of the Mental Health Status among Peasant-workers' Accompanying Children on the Demographic Variables

Gap analysis on the demographic variables finds that the mental health status of peasant-workers' accompanying children shows no difference in the variable of gender $(\mathrm{P}>0.05)$. The results are shown as follows in Table 3.

Table 3 the Comparison of Mental Health between Male and Female

\begin{tabular}{cccc}
\hline Scales & Scores of Male $[\mathrm{M} \pm \mathrm{SD}]$ & Scores of Female $[\mathrm{M} \pm \mathrm{SD}]$ & $\mathrm{T}$ \\
\hline Learning Anxiety & $8.37 \pm 3.05$ & $8.44 \pm 2.62$ & -0.33 \\
Interpersonal Anxiety & $5.26 \pm 2.31$ & $5.46 \pm 2.19$ & -1.26 \\
Lonely Tendency & $4.35 \pm 2.47$ & $4.51 \pm 2.57$ & -0.88 \\
Self-accusation Tendency & $6.18 \pm 2.29$ & $6.36 \pm 2.58$ & -1.04 \\
Sensitivity Tendency & $5.88 \pm 2.09$ & $6.11 \pm 2.09$ & -1.51 \\
Body Symptom & $6.42 \pm 3.08$ & $6.67 \pm 2.77$ & -1.18 \\
Terror Tendency & $5.13 \pm 2.51$ & $5.38 \pm 2.67$ & -1.34 \\
Impulse Tendency & $4.16 \pm 2.55$ & $4.39 \pm 2.43$ & -1.26 \\
Total scale & $45.75 \pm 14.17$ & $47.31 \pm 13.39$ & -1.57 \\
\hline
\end{tabular}

The results in Table 3 indicate that the mental problem among peasant-workers' accompanying children is not an isolated phenomenon and most peasant-workers' accompanying children often run into mental troubles.

The results also show that there is significant difference in the variables of demographic variables like parenting and only-child or not $(p<.05)$. The results were shown as follows in Table 4 and Table 5.

Table 4 the Comparison of Mental Health between Different Parenting

\begin{tabular}{cccc}
\hline Scales & $\begin{array}{c}\text { Scores of Those from } \\
\text { Authoritarian Parenting } \\
\text { Family }[\mathrm{M} \pm \mathrm{SD}]\end{array}$ & $\begin{array}{c}\text { Scores of Those from } \\
\text { Democratic Parenting Family } \\
{[\mathrm{M} \pm \text { SD] }}\end{array}$ & T \\
\hline Learning Anxiety & $9.14 \pm 2.98$ & $7.52 \pm 2.74$ & $7.90^{* *}$ \\
Interpersonal Anxiety & $5.62 \pm 2.28$ & $5.03 \pm 2.26$ & $3.64^{*}$ \\
Lonely Tendency & $4.81 \pm 2.45$ & $3.95 \pm 2.54$ & $4.80^{* *}$ \\
Self-accusation Tendency & $6.43 \pm 2.15$ & $6.06 \pm 2.46$ & $2.27^{*}$ \\
Sensitivity Tendency & $6.14 \pm 2.04$ & $5.79 \pm 2.07$ & $2.39^{*}$ \\
Body Symptom & $6.74 \pm 3.08$ & $6.28 \pm 2.89$ & $2.15^{*}$ \\
Terror Tendency & $5.56 \pm 2.88$ & $4.86 \pm 2.62$ & $3.55^{*}$ \\
Impulse Tendency & $4.47 \pm 2.63$ & $4.01 \pm 2.40$ & $2.55^{*}$ \\
Total scale & $48.86 \pm 14.41$ & $43.55 \pm 13.53$ & $5.29^{* *}$ \\
\hline$*=\mathrm{p}<.05 \cdot * *=\mathrm{p}<.01$ & & &
\end{tabular}


Table 5 the Comparison of Mental Health between Only-child and Non-only-child

\begin{tabular}{|c|c|c|c|}
\hline Scales & $\begin{array}{c}\text { Scores of Only-child } \\
{[\mathrm{M} \pm \mathrm{SD}]}\end{array}$ & $\begin{array}{l}\text { Scores of Non-only-child } \\
{[\mathrm{M} \pm \mathrm{SD}]}\end{array}$ & $\mathrm{T}$ \\
\hline Learning Anxiety & $9.24 \pm 3.08$ & $7.52 \pm 2.75$ & $7.76^{* *}$ \\
\hline Interpersonal Anxiety & $5.42 \pm 2.22$ & $5.03 \pm 2.27$ & $2.24 *$ \\
\hline Lonely Tendency & $4.49 \pm 2.65$ & $3.95 \pm 2.48$ & $2.72 *$ \\
\hline Self-accusation Tendency & $6.44 \pm 2.58$ & $6.06 \pm 2.41$ & $2.00 *$ \\
\hline Sensitivity Tendency & $6.15 \pm 2.10$ & $5.79 \pm 2.09$ & $2.22 *$ \\
\hline Body Symptom & $6.74 \pm 3.08$ & $6.28 \pm 2.89$ & $2.01 *$ \\
\hline Terror Tendency & $5.36 \pm 2.56$ & $4.86 \pm 2.71$ & $2.42 *$ \\
\hline Impulse Tendency & $4.44 \pm 2.66$ & $4.01 \pm 2.43$ & $2.21 *$ \\
\hline Total scale & $48.28 \pm 14.13$ & $43.55 \pm 13.73$ & $4.39 * *$ \\
\hline
\end{tabular}

$*=\mathrm{p}<.05 ; * *=\mathrm{p}<.01$

The results in Table 4 and Table 5 indicate that family is becoming a more and more important factor affecting one's mental health.

\section{Discussion}

The survey shows that the mental health status of peasant-workers' accompanying children is generally poor, which is basically identical with the most results of domestic researches. It indicates that the environmental changes during the course of immigrating and their social cognition as vulnerable group may have obvious negative effect on their mental health. It also shows that one's inner mental factors (such as expected discrimination, coping style, sense of self-efficacy, mental preparation for immigration and so on) [7] and outer environmental factors (such as parenthood, social support, dual urban and rural household registry system and so on) [1] are closely related to his or her mental health. So, in order to promote their mental health level, it is necessary to conduct mental health education for them with the contributions of family, school and society.

Generally speaking, family plays an irreplaceable role in maintaining mental health. The quality of home environment directly affects one's mental health. Poor communication and lack of love are the important factors that bring mental problems to peasant-workers' accompanying children. So, parents should change their mindset, value children's mental health, and pay more attention to the changes and thoughts after immigration. It is also necessary for them to conduct positive and effective communicating with children, and give them more love to decrease negative impact on their mental health during environmental transition. When the children feel any discomfort in the life or learning of ingoing place, parents should give them necessary guidance, praise them more, and guide them to adapt to the life and learning of ingoing place as soon as possible to eliminate their mental problems like sense of inferiority, self-accusation, autism, anxiety and so on. At the same time, parents should also set good examples for children. When suffering difficulties and setbacks, parents should keep a positive attitude instead of a negative one in front of children so that the children can establish self-confidence.

School plays significant guiding roles in developing one's physical and mental health. In order to ensure children to grow in a healthy way, school should create a good atmosphere for peasant-workers' accompanying children to live and learn. Firstly, school should build a mental health database for students and reinforce the management. The general survey of mental health should be developed actively to get a comprehensive understanding of their mental health. Mental guidance to the children also should be carried out positively. Secondly, School should strengthen the work of mental health education. In order to develop the abilities of anti-frustration, adaptation and self-regulation, school should not only establish special courses for mental health education, but also make the concept of mental health education penetrate into teaching work of each course so that the solid education network of mental health can be built. Thirdly, school should introduce appropriate measures and incentive systems based on the actual situation so as to directly provide learning guidance to peasant-workers' accompanying children, which inspires their passion for 
learning, and enables them to fit into local school life as soon as possible. Finally, school should encourage local students to associate actively and positively with peasant-workers' accompanying children. School also should urge immigrating students to actively join in all kinds of after-school clubs so that they can continually find pleasure of life and learning during the course of associating with local students, which will greatly improve the level of immigrating students' mental health.

Society serves as a subtle influence on one's sound development. So, different sectors of the society should try the best to create a good living and learning atmosphere for the immigrating students' sound development. Firstly, in order to offer peasant-workers' accompanying children positive energy, different sectors of the society should strengthen the construction and management of the peasant-workers' rental housing, build a good social atmosphere, and try to eliminate the effects of negative factors. Secondly, to make peasant-workers' accompanying children feel the love and warm of the society, different sectors of the society should care and concern them more to remove their social recognition of inequality. Finally, it is necessary to establish a sound social mental guidance system of all levels and all kinds. The guidance centers for the minor's healthy growth across the country should intervene actively, and make the best of new media to propagate the relevant knowledge of how to keep and improve mental health.

In short, to fundamentally improve the mental health status of peasant-workers' accompanying children, it is necessary to fully mobilize the power from family, school and society to form a good atmosphere for their healthy growth. Different sectors of the society should work together to promote mental health level of peasant-workers' accompanying children.

\section{References}

[1] Xiong Meng, Ye Yi-duo, Mental Health for the Children of Farmers Who Worked in City in China, Advances in Psychological Science, 2011, 19(12): 1798-1813.

[2] Shen Ji-liang, Fang Xiao-yi, Wang Jian-ping, et al, Disadvantaged Children's Psychological Development and Educational Countermeasures, Economic and Scientific Press House, Beijing, 2009.

[3] Lin Xiu-yun, Fang Xiao-yi, Liu Yang, et al, The Effect Mechanism of Stigma Perception on Mental Health Among Migrant Children in Beijing, Acta Psychologica Sinica, 2009, 41(10): 967-979.

[4] Han Xuan,Wu Han-rong, Mental Health Status of Floating Children in Shenzhen, Chinese Journal of School Health, 2010, 31(1): 64-65.

[5] Bhugra, D., Migration and Mental Health, Acta Psychiatrica Scandinavica, 2004, 109(4): $243-258$.

[6] Zhou Bu-cheng, Mental Health Test Handbook, East China Normal University Press, Shanghai, 1991.

[7] Jasinskaja-Lahti, I., Yijälä, A., The Model of Pre-acculturative Stress - A Pre-migration Study of Potential Migrants from Russia to Finland, International Journal of Intercultural Relations, 2011, 35(4): 499-510. 